\title{
Two-phase transverse flux machine with disc rotor for high torque low speed application
}

\author{
Sebastian Hieke, Mario Stamann, \\ Dmytro Lagunov, Roberto Leidhold \\ Otto-von Guericke-Universität \\ Universitätsplatz 2 \\ 39104 Magdeburg, Germany \\ Phone: +49 0391-67-54898 \\ Fax: +49 0391-67-12481 \\ Email: sebastian.hieke@ovgu.de \\ URL: http://www.ovgu.de
}

\author{
Andrii Masliennikov, Aleksei Duniev, \\ Andrii Yehorov \\ National Technical University \\ Kharkiv Polytechnic Institute \\ Kyrpychova str. 2 \\ 63101 Kharkiv, Ukraine \\ Phone: +38 057-707-65-14 \\ Email: x-maslennikov@yandex.ua \\ URL: www.kpi.kharkov.ua
}

\section{Keywords}

$\ll$ Transverse flux motor $\gg, \ll$ Efficiency $\gg, \ll$ Renewable energy systems $\gg, \ll$ Design $\gg, ~ \ll$ Permanent magnet motor $\gg$

\begin{abstract}
This paper presents a special two-phase transverse flux machine with disc rotor. Because of the noncomplex construction and by using simple 2D flux path and 3D printing methods the manufacturing costs are hold low. A design criterion is proposed for maximizing the torque density in the low speed range. To prove the concept and analyse the potential of this construction a first direct driven prototype was built. The experimental results confirm the viability of this proposal and provide the required information for further enhancements.
\end{abstract}

\section{Introduction}

The present work deals with a special design of transverse flux machines. Transverse flux machines (TFM) is a kind of synchronous machines with a particular concept for the flux path. It consists of a rotor with permanent magnets and a stator coil, which is enclosed by a toothed steel structure (Figure 1).
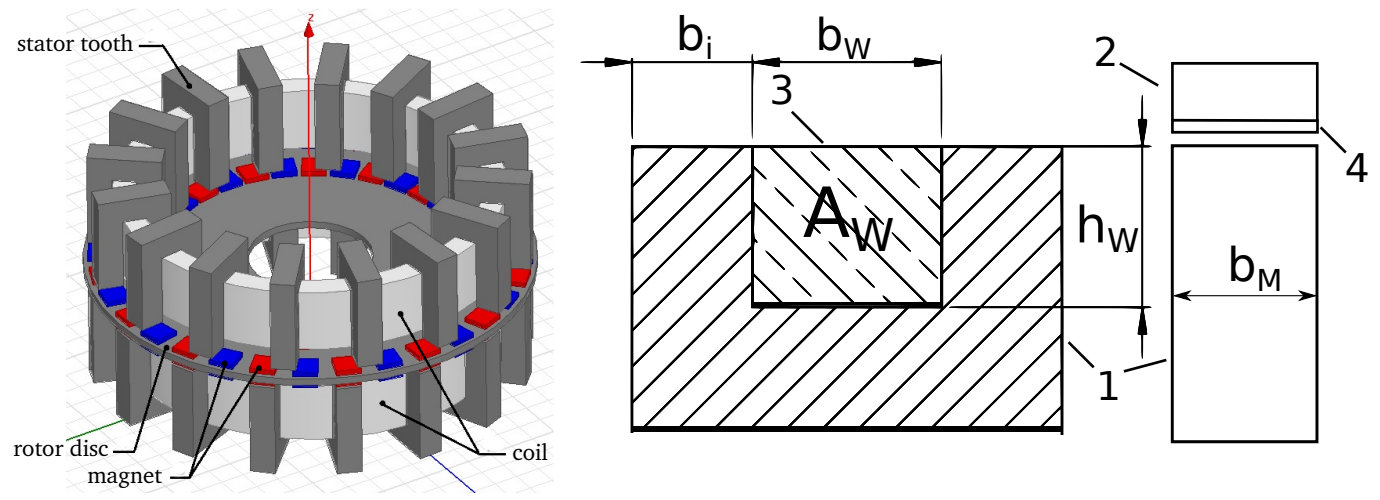

Fig. 1: Complete model of the transverse flux machine with disc rotor and model of one tooth: 1-tooth, 2-iron back, 3-coil, 4-permanent magnet

The TFM is capable of a very high torque per volume and mass in the low speed range [1]. Strong ripple torque and a low power factor at full load are major drawbacks of such machines. Nevertheless 
its construction can be simple. Especially, the winding consists only on a ring coil per phase, unlike conventional machines with distributed or concentrated windings, which require several coils per phase. Furthermore, the teeth are made of conventional electrical steel sheets and its U-form allows a simple manufacturing.

What we aim at with this paper is to design a TFM generator with the simplest possible construction for use in renewable energy generation. For example, hydrokinetic power stations can be used to gain energy from river streams as off-grid generation in sparse populated regions, where power grids are not available. Figure 2 shows a testing plant of a small horizontal water wheel with a diameter of $0.75 \mathrm{~m}$. It is used for drinking water purification. This is a candidate application for the TFM.

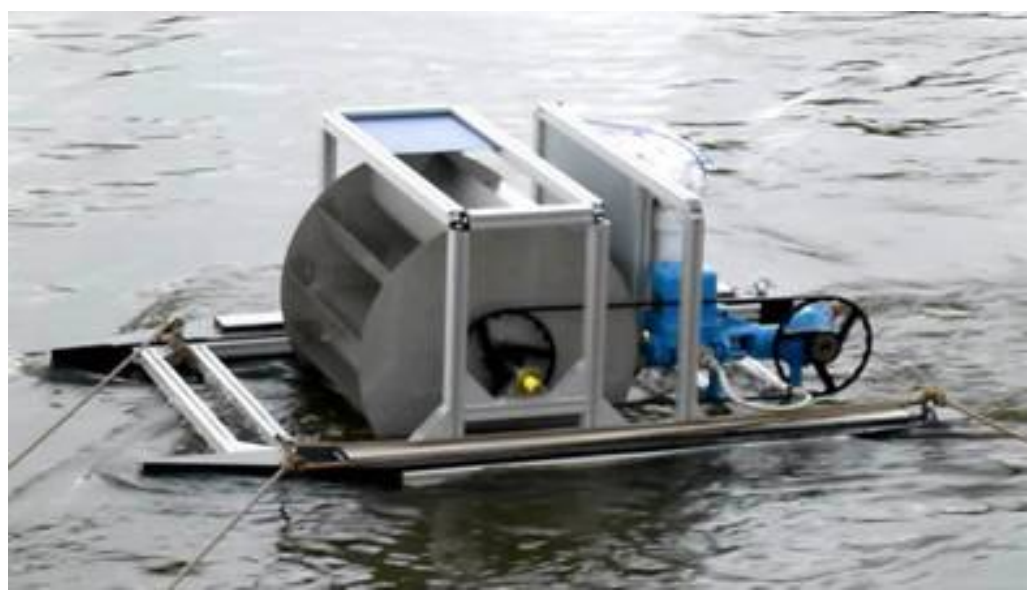

Fig. 2: testing plant of a small horizontal river water wheel for drinking water purification

For electric power generation a high efficiency generator is needed, because the maximum mechanical power of the water wheel is limited by the stream speed of the river. Most efficient energy conversion can only be reached by using a direct driven generator without gearbox. Therefore this paper deals with the design of an unconventional generator, which is working at low speed with high torque and high efficiency. To reduce the payback period of the power station, also production costs of the generator have to be as low as possible.

Several scientific articles were published about machines with a disc rotor. The form factor (high diameter to length-ratio) of such machines is suited for direct drive applications. These are mostly axial flux machines, using concentrated windings and surface mounted magnets [2]. In [3] the axial flux machine is proposed for application in wind power plants, as a low speed gearless generator. In [4] a TFM with disc rotor is presented, which is based on the switched reluctance principle. However, the complexity is quite high, requiring six windings and three discs. Another prototype of a TFM with only one disc is introduced in [5]. In that topology the flux actually does not closes through the disk but radially through rings attached to the disc. A drawback of that proposal is that the flux of the stator cores has a 3D flux path, which makes the realization more difficult.

\section{Proposal}

In this paper a two-phase transverse flux machine with a disc rotor for high torque low speed applications is proposed. Figure 1 shows a model of the machine with two coils enclosed by the teeth. The rotor consists of a circular massive steel disc and surface-mounted magnets for each phase. The disc does not need to be laminated due to the low frequency at low speed and expectable slight eddy current losses.

As there is one disc-side required for each phase of the TFM, a three phase machine would require two discs. Consequently, it was chosen to use only two phases for a simpler design with only one disc. Furthermore, the design of the teeth is kept in the configuration as proposed by Weh [6]. Thereby the magnetic flux is limited to only two dimensions, unlike usual configurations that require flux in three dimensions. For this reason the tooth can be made of laminated steel, rather than soft magnetic composites needed for a three dimensional flux path [7]. The teeth are U-shaped as shown in figure 1. 
To allow a simple modular production of the machines of different ratings (speed, torque) the tooth shape is kept constant. That is $b_{i}, b_{w}$ and $h_{w}$ in figure 1 . Just the stack height $b_{m}$ is variable, which together with the additive-manufactured parts allow to flexibly arrange the number of pole pairs depending on the area of application, rated torque and rated speed.

Table I: Parameters of the TFM

\begin{tabular}{lcr}
\hline Quantity & Symbol & Value \\
\hline Rated torque & $T$ & $10 \mathrm{Nm}$ \\
Speed & $n$ & $100 \mathrm{rpm}$ \\
Height & $H$ & $180 \mathrm{~mm}$ \\
Axial length & $l$ & $110 \mathrm{~mm}$ \\
Width & $W$ & $180 \mathrm{~mm}$ \\
Radius & $\mathrm{r}$ & $73 \mathrm{~mm}$ \\
Rated Power & $P$ & $100 \mathrm{~W}$ \\
Air-gab length & $g$ & $1 \mathrm{~mm}$ \\
Magnet thickness & $h_{m}$ & $2 \mathrm{~mm}$ \\
Pole pairs & $p$ & 32 \\
Number of turns & $N_{t}$ & 280 \\
Coil resistance & $R$ & $4.4 \Omega$ \\
Coil Inductance & $L$ & $76 \mathrm{mH}$ \\
\hline
\end{tabular}

Not only the magnetic circuit should be of simple construction, also the mechanical components, like the bearing plates, will be kept as simple as possible. Therefore additive manufacturing is used for most parts of the machine, which are not moving and not in the magnetic flux path. Some precedence can be found in [8], where an axial flux machine using composite plastic materials is investigated.

Figure 3 shows the disassembled machine (left), where the rotor and both stators parts can be appreciated, as well as the assembled machine (right). In figure 4 the machine is shown mounted on the test rig. The stator cases are 3D-printed with a fill factor of $50 \%$ to ensure adequate stability. As can be seen, there are different recesses and slots, the former is for saving materials the latter is to plug in the U-Cores and the bearing. The ring-coil is placed inside the U-Cores. This clearly shows the advantage of such coils, which can be winded in a separated step and thereafter placed and fixed with an epoxy resin into the case.
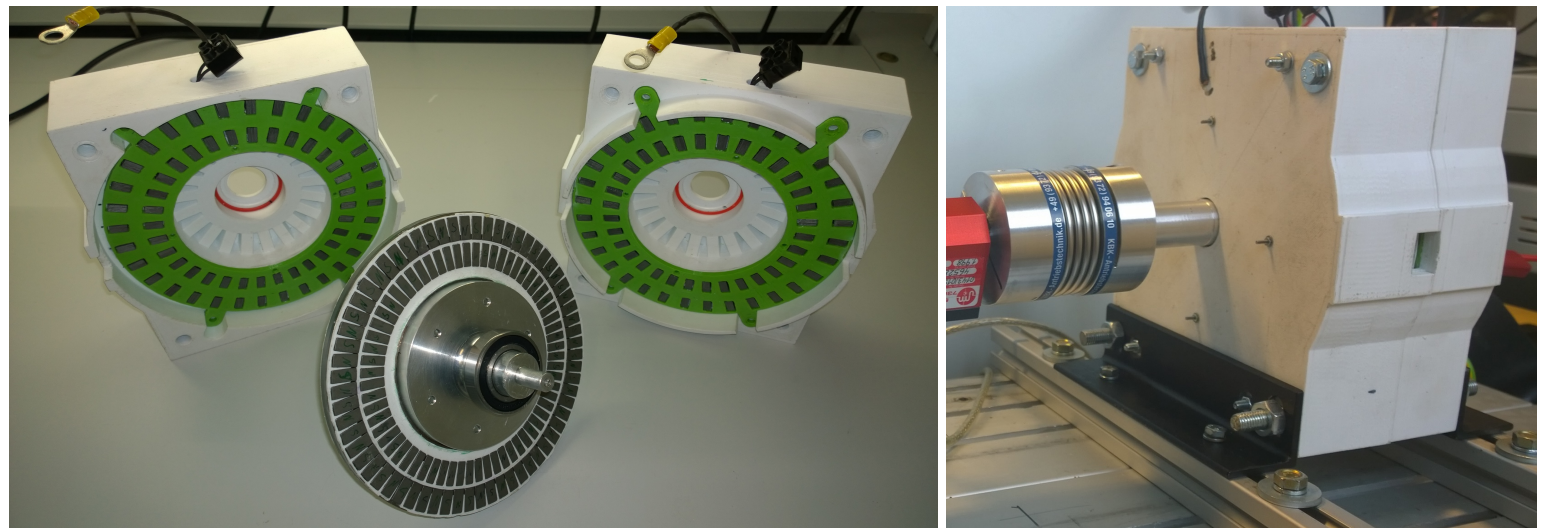

Fig. 3: Prototype of the two-phase TFM with disc rotor

The use of plastic materials together with additive manufacturing methods allows a highly flexible production, which offers the possibility to produce cheap generators for a small number of units, especially for prototyping. This can also be a disadvantage due to higher tolerances in the geometry, which in turns lead to increasing cogging torque, increasing harmonics of the back-EMF and therefore to more ripple 
torque. However, several scientific articles have shown that it can be effectively be reduced by means of an active (control base) torque ripple compensation as can be found in [9] and [10]. Based on the method in [10], the torque ripple of the proposed TFM with disc rotor was minimized, as detailed in section 4.

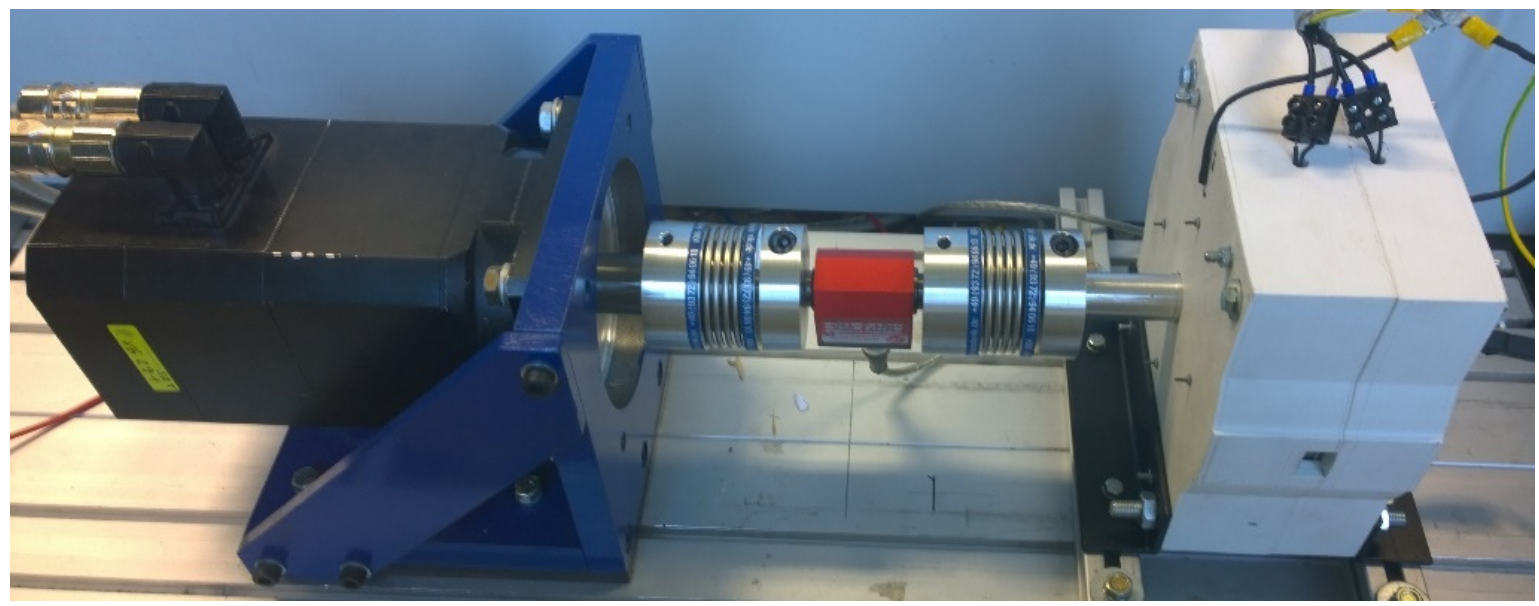

Fig. 4: Prototype of the two-phase TFM with disc rotor on the test rig

The whole structure of the stator is made of PLA except teeth and coils, as shown in figure 3. Certainly, this affects the power rating of the machine due to the maximal allowed temperature and material strength. Conventional rotary machines with air cooling operate with a current density of $3-6 \mathrm{~A} / \mathrm{mm}^{2}$. The prototype presented in this paper uses a maximum current density of $3 \mathrm{~A} / \mathrm{mm}^{2}$, because of the low maximal temperature allowed by the frame material.

\section{Geometry and force optimisation}

The number of pole pairs and consequently the pole pitch is only in a close range alterable to get an optimal yield of torque per volume. Figure 5 shows the torque characteristic of the disc rotor TFM for a constant diameter and MMF, depending on the number of pole pairs, as computed by the finite element method (FEM). By a given air gap, a small pole pitch leads to high leakage flux, while a wide pole pitch decreases $\mathrm{dB} / \mathrm{d} \vartheta$ in the air gap, and consequently the torque. Where $B$ is the flux density and $\vartheta$ is the angular position of the rotor.

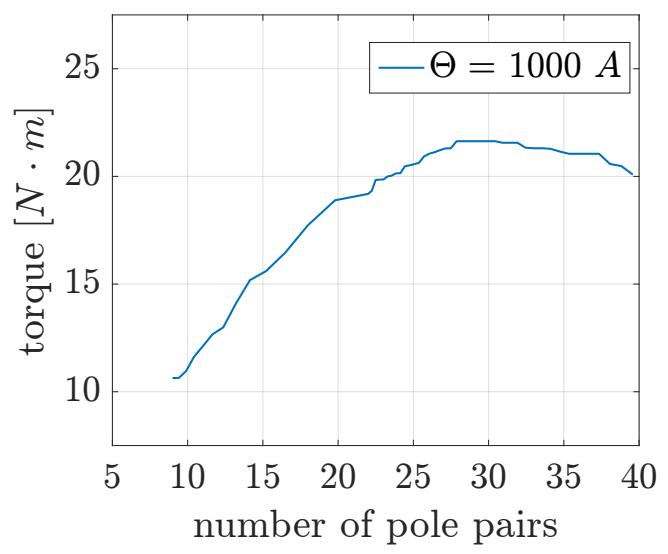

Fig. 5: Torque dependent on number of pole pairs computed by FEM; MMF is 1000A

The rating of the torque can be improved by further modifications of the magnetic circuit. The winding sections between two U-Cores are linked with the leakage flux of the exposed magnets. It is important to note, that this flux is in opposite direction than the flux in the U-Cores. Thus it appears that a negative 
torque component is produced, reducing the total torque of the machine [11]. To avoid this effect an additional I-Core is placed between two U-Cores. Consequently, the leakage flux of the exposed (i.e. inverted) permanent magnets is not linked with the windings any more and the back-EMF and torque increases. Both machines versions i.e. without and with I-cores are investigated in the next section.

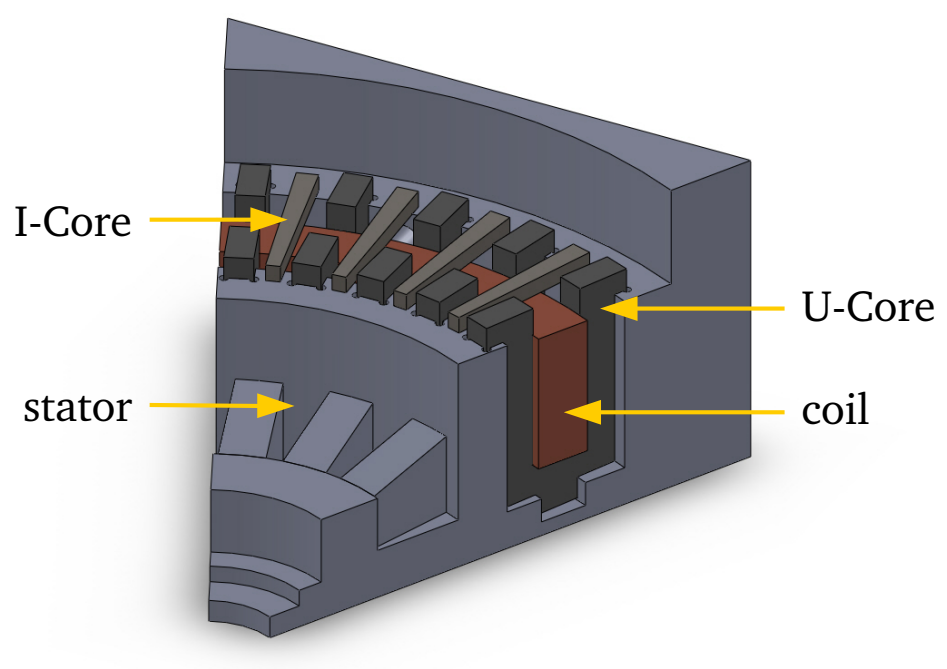

Fig. 6: Magnetic circuit modification by adding I-cores between the U-cores for increasing the EMF and torque

\section{Results}

A first prototype was built in two versions to validate the proposal, as shown in figure 3. Figure 7 shows the position-derivative of the flux-linkage calculated from the measured back-EMF and speed for both versions according to (1).
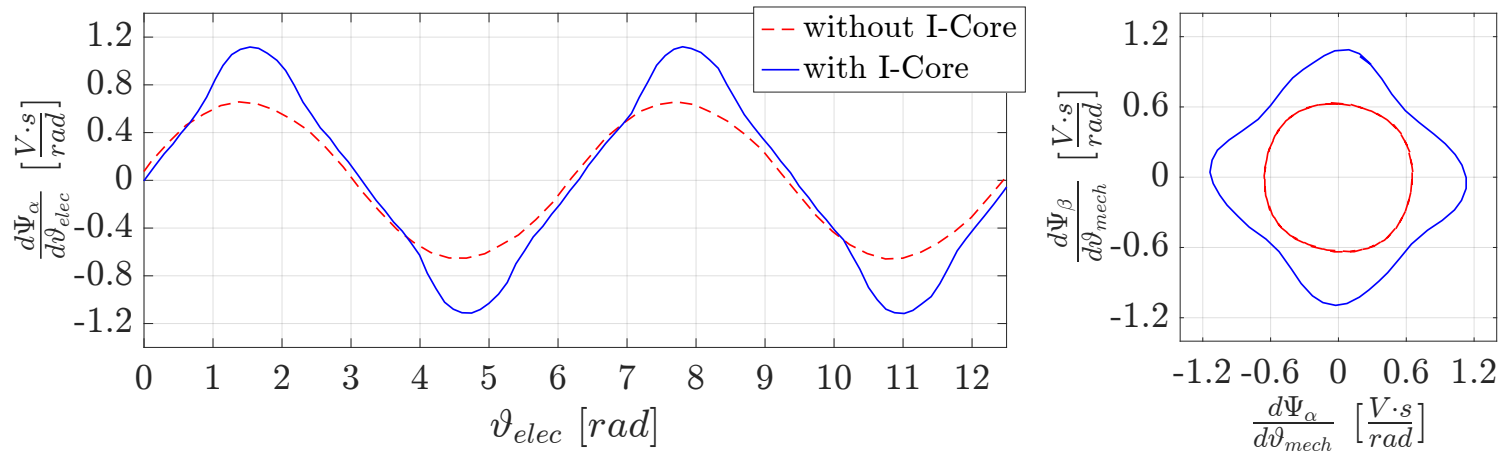

Fig. 7: Position-derivative of the flux linkage as function of the position i.e. the EMF per speed unit

The position-derivative of the flux-linkage can also be considered as the back-EMF per speed unit, which is a characteristic of the machine. Both curve characteristics are notably different from each other. On the one hand the version without I-Cores gives a near to sinusoidal wave form, contrary to the second version with a near triangular waveform. The magnet flux of the permanent magnet is shorten when facing of the I-Cores and concentrated when facing the U-cores providing a sharper transition, which leads to the near triangular waveform.

$$
u_{i}=\frac{d \Psi}{d t}=\frac{d \Psi}{d \vartheta} \frac{d \vartheta}{d t}=\frac{d \Psi}{d \vartheta} \cdot \omega
$$


Where $u_{i}$ is the induced voltage, $\Psi$ is the flux linkage and $\omega$ is the angular speed. The increase in the RMS value clearly shows the advantage of the prototype with I-Core, for instance the calculated RMS values are given in table II. Comparison of the torque per-unit volume shows that the modified machine produced 1.5 times the torque per unit volume than the machine without I-cores. Consequently, it is possible to reduce the current for an equivalent output power and therefore the copper losses decrease.

Table II: Comparision of

\begin{tabular}{llr}
\hline Quantity & Symbol & Value \\
\hline RMS of derivative of the flux linkage without I-Cores & $\left(\frac{d \Psi_{\alpha}}{d \vartheta_{\text {elec }}}\right)^{r m s}$ & $0.476 \frac{\mathrm{V} \cdot \mathrm{s}}{\mathrm{rad}}$ \\
RMS of derivative of the flux linkage with I-Cores & $\left(\frac{d \Psi_{\alpha}}{d \vartheta_{\text {elec }}}\right)^{r m s}$ & $0.723 \frac{\mathrm{V} \cdot \mathrm{s}}{\mathrm{rad}}$
\end{tabular}

The torque ripple at $10 \mathrm{rpm}$ of the proposed TFM is shown in figure 8 . It is around $17.5 \%$ of the rated torque. For analysis purpose, the frequency spectrum is given in the same figure. By comparing the torque variation at full load for both machine types, it can be recognised that the second prototype has a slightly reduced torque ripple. A valuable improvement in minimizing the torque ripple for both machines is gained by compensating the frequency components twofold, fourfold and sixfold of the TFM supply frequency [10], thereby decreasing the torque ripple from around $15-17.5 \%$ to $2.5-5 \%$.
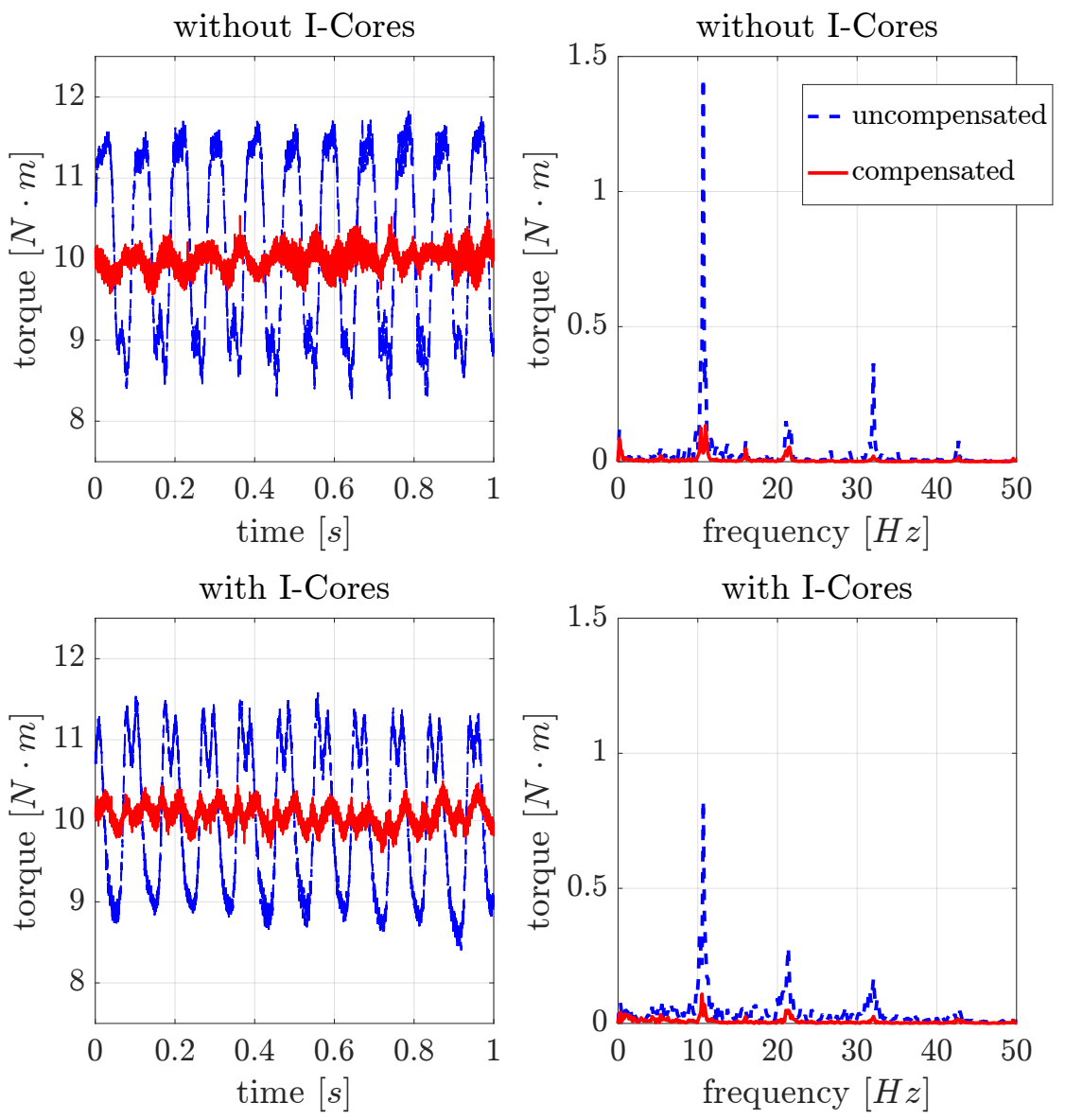

Fig. 8: Comparison of the torque ripple at $10 \mathrm{rpm}$ 
Figure 9 illustrates the control scheme of the realised compensation method. The Park transformation of stator related variables $u_{a}, u_{b}, u_{c}$ and $i_{a}, i_{b}, i_{c}$ into rotor orientated variables $u_{d}, u_{q}$ and $i_{d}, i_{q}$ is performed through $T$, using the electrical rotor angle $\theta_{e l}$ for field orientation.

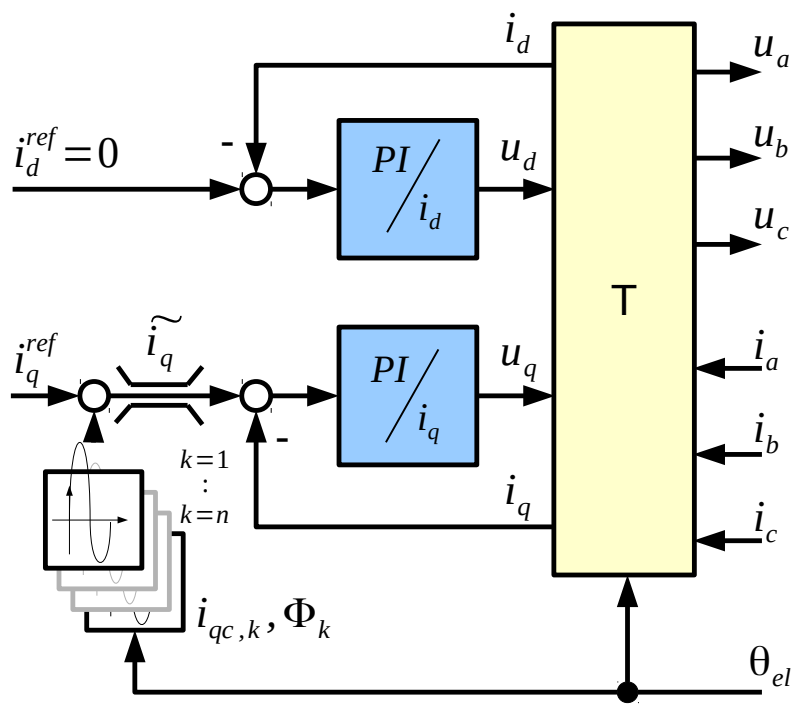

Fig. 9: Control scheme of ripple torque compensation by feed-forward set-point control in rotor orientated coordinates $d$ and $q$

Two PI-controllers are used to control $i_{d}$ and $i_{q}$ separately and are optimised by the amplitude optimum criterion. It is not necessary to utilise every frequency component. This should be done dependent upon the frequency spectrum of the torque ripple. Magnitude $\hat{i}_{q c, k}$ and phase shift $\phi_{k}$ have be adjusted according to load and rotating direction [10].

Figure 10 shows the efficiency of the proposed TFM with and without I-Cores, as a function of the speed and for a constant torque of $10 \mathrm{Nm}$. The proposed concept without I-Cores is able to achieve a maximum efficiency of $80 \%$ at around $100 \mathrm{rpm}$, when iron loss equals copper loss. Further increasing of the speed has negative effects due to higher iron losses. In Contrast, the TFM with I-Cores achieves the maximum efficiency at $40 \mathrm{rpm}$, due to the reduced copper losses but additional iron losses in the I-Cores. This prototype uses I-Cores made of massive steel, rather than laminated steel leading to higher iron losses in the additional cores.

As for comparison, the efficiency for a $120 \mathrm{~W}, 8$ poles induction machine with efficiency class IE4 (EN 60034-30-1) is $62.3 \%$. Here still a gearbox has to be used to reach the required speed, which will reduce the overall efficiency even more.
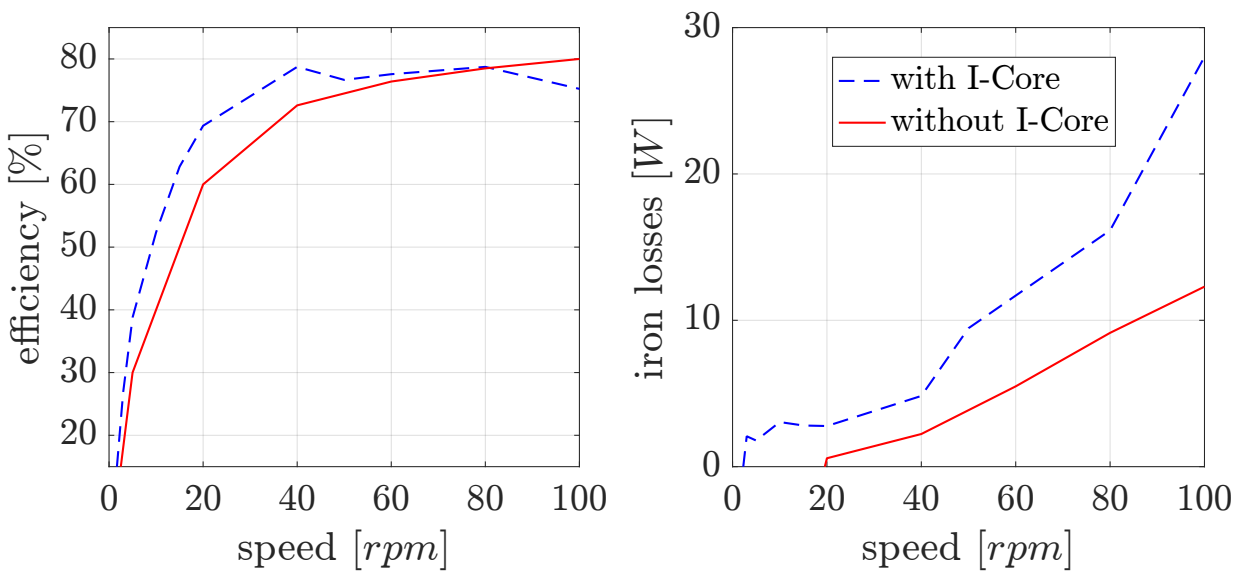

Fig. 10: Efficiency and iron losses at $10 \mathrm{~N} \cdot \mathrm{m}$ 
The chosen concepts provides the opportunity for using a ring coil, which could be prepressed in a die to increase the fill factor and consequently minimize the resistance $R$ of the TFM. Thus copper losses and the resistance could be reduced by $20 \%$ by increasing the copper fill factor from $60 \%$ to $80 \%$ [12]. This would lead to a slight improvement of the efficiency from $80 \%$ to around $82 \%$ at $100 \mathrm{rpm}$ in the machine without I-Cores.

Table III: Inductance of the TFM

\begin{tabular}{lcr}
\hline Quantity & Symbol & Value \\
\hline direct-axis Inductance & $L_{d}$ & $76 \mathrm{mH}$ \\
quadrature-axis Inductance & $L_{q}$ & $78.4 \mathrm{mH}$ \\
\hline
\end{tabular}

In order to analyse the self sensing capability of the machine the inductance was measured as function of the position. From this measurement, the direct-axis inductance $L_{d}$ and the quadrature-axis inductance $L_{q}$ were determined. They show a difference of only $3 \%$, which in general is to low implement self sensing methods.

\section{Conclusion}

A two phase transverse flux machine with disc rotor has been successfully manufactured and tested. The motor should provide an easy way of manufacturing and a high efficiency at low speed. Both aims were achieved for two different prototypes. It has been showed, that there is potential for further improvements, like prepressed windings and I-Cores made of laminated steel sheets to reduce copper and iron losses.

\section{References}

[1] H. Weh, H. May, Achievable force densities for permanent magnet excited machines in new configurations, in Proc. International Conference on Electrical Machines, 1986, pp. 1107-1111

[2] M. Aydin, S Huang, T. A. Lipo, Optimum Design and 3D Finite Element Analysis of Non-slotted and Slotted Internal Rotor Type Axial Flux PM Disc Machines, Electric Machines and Drives Conference, 2001, pp. $1409-1416$

[3] A. Parviainen, J. Pyrhnen, P. Kontkanen, Axial Flux Permanent Magnet Generator with Concentrated Winding for Small Wind Power Applications, Electric Machines and Drives, 2005, pp. 1187- 1191

[4] J. Doering, W. Hofmann, Design of a transverse flux reluctance machine with mutual flux paths and disc rotors, Power Electronics and Applications (EPE), 2015

[5] S. M. Husband, C.G. Hodge, The Rolls-Royce transverse flux motor development, Electric Machines and Drives Conference, vol. 3, 2003, pp. 1435-1440

[6] H. Weh, J. Jiang, Berechnungsgrundlagen fr Transversalflussmaschinen, Archiv fr Elektrotechnik, vol. 71, 1988, pp. $187-198$

[7] ] J. G. Washington, G. J. Atkinson, N. J. Baker, A. G. Jack, B. C. Mecrow, B. B. Jensen, L. O. Pennander, G. L. Nord, L. Sjberg, Three-Phase Modulated Pole Machine Topologies Utilizing Mutual Flux Paths, Transactions on Energy Conversion, vol. 27, 2012, pp. 507-515

[8] F. Profumo, A. Tenconi, M. Cerchio, J. F. Eastham, P.C. Coles, Axial Flux Plastic Multi-Disc Brushless PM Motors: Performance Assessment, Applied Power Electronics Conference and Exposition, 2004, pp. $1117-1123$

[9] J. Klck, T. Orlik, W. Schumacher, Modeling and Torque Ripple Minimization of Transverse Flux Machines, Power Electronics and Applications (EPE), 2013

[10] S. Hieke, M. Stamann, R. Leidhold, Compensation of Production and Principle Related Torque Fluctuations of Transverse Flux Machines, Innovative small Drives and Micro-Motor Systems (IKMT), 2015, pp. 140-144

[11] J. R. Anglada, S. M. Sharkh, "An insight into torque production and power factor in transverse-flux machines", Electrical Machines (ICEM), 2016

[12] A. G. Jack, B. C. Mecrow, P. G. Dickinson, D. Stephanson, J. S. Burdess, N. Fawcett, J. T. Evans, ” Permanent-Magnet Machines with Powdered Iron Cores and Prepressed Windings", IEEE Transactions on Industry Applications, vol. 36, no. 4, 2000 